\title{
Attachment Style and Political Ideology: A Review of Contradictory Findings
}

\author{
Spassena P. Koleva · Blanka Rip
}

Published online: 9 July 2009

(C) The Author(s) 2009. This article is published with open access at Springerlink.com

\begin{abstract}
Relational attachment style - a lifespan factor whose first manifestation at the age of 6 months continues into old age-has recently been theoretically and empirically linked to political ideology. A review of the literature that links these two constructs reveals a conflicting pattern. Secure attachment is predominantly associated with liberalism and its covariates, although the relationship is not robust, and there are some exceptions. Insecure avoidant attachment is associated with both liberalism and conservatism, along with their respective covariates. Finally, insecure anxious-ambivalent attachment is associated with covariates of conservatism. We propose a tentative distinction between motivational conceptualizations of attachment as a relational need and of attachment as a relational habit, which may help to clarify the relationship between attachment style and political ideology.
\end{abstract}

Keywords Attachment style $\cdot$ Mental models · Ideology · Liberalism · Conservatism

Mental models regarding the accessibility and responsiveness of attachment figures - that is, relational attachment styles-first emerge in infancy (Bowlby, 1973) and remain relevant across the lifespan (Cassidy, 1994; Fraley \& Shaver,

Both authors contributed equally to this study.

S. P. Koleva $(\bowtie)$

University of California, Irvine, CA, USA

e-mail: skoleva@uci.edu

B. Rip

Université du Québec à Montréal, Montréal, QC, Canada

e-mail: rip.blanka@courrier.uqam.ca 
2000; Hazan \& Shaver, 1987; Shaver \& Mikulincer, 2002; Trinke \& Bartholomew, 1997). The attachment behavioral system evolved to promote survival by motivating infants to seek proximity to their primary caregiver, especially under threatening circumstances (Bowlby, 1973). In addition to protection from threats, infants use their attachment figure as a secure base from which to explore and learn about their environment (Ainsworth, 1991; Bowlby, 1973; Waters, 2002). Depending on the availability and responsiveness of childhood attachment figures, individuals develop internal working models of relationships that persist in adulthood (Hazan \& Shaver, 1987). These working models are reflected in the development of secure or insecure attachment, or relational, styles. In turn, attachment styles influence individuals' sense of security and worldviews, both of which have been linked to political ideology (Duckitt, 2001; Jost, Glaser, Kruglanski, \& Sulloway, 2003). Thus, the attachment literature is relevant to the study of ideology because personal attachment history and style may come to shape political preferences.

There has been a recent upsurge of interest in the social and psychological processes that underlie political ideology. This body of research has generally focused on the situational and dispositional variables that predict political conservatism. The research focus on conservatism is hardly surprising given the threat and uncertainty engendered by international instability since $9 / 11$, which heralded the (re)election of conservative governments in Western countries including the U.S., Canada, France, and Switzerland. Whereas a considerable debate exists on whether political ideology is best conceptualized on a single dimension (with opposite liberal and conservative poles) or as a multidimensional construct (e.g., distinct social and economic components), the majority of the studies we review here appear to use the former approach; therefore, we have adopted a similarly unidimensional view. Thus, people who score low on conservatism score high on liberalism and vice versa. In this article, we define conservatism as the tendency to resist change and endorse social inequality (Jost et al., 2003); in contrast, liberalism is defined as the tendency to embrace change and condemn social inequality.

Several situational and dispositional covariates of ideological self-placement have been identified (Alford, Funk, \& Hibbing, 2005; Block \& Block, 2006; Bonanno \& Jost, 2006; Caprara \& Zimbardo, 2004; Jost et al., 2003; McCrae, 1996). Recently, attachment style has also been theoretically and empirically linked to political ideology, albeit in discrepant ways. The majority of studies have linked secure attachment to liberalism or covariates of liberalism and insecure attachment to conservatism or covariates of conservatism (e.g., Gillath \& Hart, in press; Weber \& Federico, 2007; Weise et al., 2008). However, some notable exceptions exist. For example, some studies find that individuals with avoidant attachment style-a subtype of insecure attachment-do not appear to be conservative and generally behave very similarly to those with secure attachment and/or liberal orientation (e.g., Thornhill \& Fincher, 2007).

The goal of this review is to summarize and weigh the available evidence concerning the relationship between attachment style and political ideology. To this end, we have included studies that link these constructs both directly and indirectly 
(in which correlates of attachment style are linked to correlates of political ideology). In the last section, we discuss avenues for future research that may help to resolve the contradictory findings. We then propose a theoretical distinction between two motivational conceptualizations of attachment as the basis for adopting a political ideology — attachment as a relational need and attachment as a relational habit.

\section{Attachment Theory}

The primary function of attachment is to provide protection and a sense of security (Ainsworth, 1991). According to the developmental perspective, confidence regarding the accessibility of an attachment figure is fashioned in infancy, childhood, and adolescence, and it persists relatively unchanged throughout the person's life (Bowlby, 1973). That is, idiosyncratic developmental experiences become reflected in generalized mental models regarding the accessibility and responsiveness of attachment figures. These mental models translate into three relational or attachment styles - secure, avoidant, and anxious-ambivalent-which are manifest from infancy and childhood in relation to caregivers (Ainsworth, Blehar, Waters, \& Wall, 1978), and throughout adulthood in relation to one's romantic partners (Hazan \& Shaver, 1987), friends, and other attachment figures (Cassidy, 1994; Fraley \& Shaver, 2000; Shaver \& Mikulincer, 2002; Trinke \& Bartholomew, 1997).

Two orthogonal dimensions underlie this categorical characterization of attachment, namely, attachment avoidance and attachment anxiety-ambivalence (Brennan, Clark, \& Shaver, 1998; Griffin \& Bartholomew, 1994). Scoring low on both of these dimensions indicates a secure attachment style. In contrast, scoring high on either dimension indicates an insecure attachment style. Insecure avoidant attachment (also called dismissive in adulthood) is characterized by high avoidance and low anxiety, whereas insecure anxious-ambivalent attachment (also called preoccupied in adulthood) is characterized by high anxiety and low avoidance.

Securely attached infants tend to explore their surroundings and environment in their caregiver's presence, stay open to contact with strangers, become distressed upon separation with the caregiver, and are happy to see her ${ }^{1}$ upon return (Ainsworth et al., 1978). Later in life, securely attached adults are comfortable with being intimate with, depending on, and being depended upon by others. Such adults worry neither about being abandoned nor about getting too close to their partners (Hazan \& Shaver, 1987).

In contrast, avoidantly attached infants tend to explore their environment less and to ignore their primary caregiver and strangers. They are neither distressed by

\footnotetext{
1 Although Ainsworth et al.'s (1978) pioneer study was almost exclusively concerned with mother-infant attachment, more recent research has also examined father-infant attachment (e.g., Lamb, 1997). The mother-child attachment literature continues, however, to be relatively richer than the father-child attachment literature. One reason for this may be the slow pace of social norm and policy change (e.g., paid and government subsidized paternity leave) in most Western countries, without which fathers are unable and/or unwilling to equally share in the primary childcare responsibilities.
} 
separation from nor pleased by being reunited with their primary caregiver. Avoidant (dismissive) adult attachment is characterized by discomfort in being close to others, as well as difficulty trusting and depending on them. Such adults feel nervous when anyone gets too close-they feel that their romantic partner often wants to be more intimate with them than they would like to be. In addition, some researchers identify a second avoidant type in adulthood, called fearful-avoidant, which is characterized by both high avoidance and high anxiety (Bartholomew \& Horowitz, 1991). These individuals have mixed feelings about close relationships; they desire emotionally close relationships but are uncomfortable with intimacy. However, the majority of the studies reviewed here do not include this fourth attachment type in their conceptualization, thus we have limited our discussion to the first three styles.

Finally, anxious-ambivalent infants are also reluctant to explore their environment and are not open to contact with strangers, but they are highly distressed when left alone by the primary caregiver and inconsistent in their behavior upon her return; in addition, they cry more than usual and alternate between attachment behavior and expressions of anger. In adulthood, anxious-ambivalent individuals worry a lot about their relationships and feel that others are reluctant to get as close as they would like them to. That is, these adults would like to merge with others, but find that their desire scares people away, all of which contributes to their concerns about whether their partner really loves them and wants to stay with them (Hazan \& Shaver, 1987).

Attachment in children is typically assessed using the Strange Situation paradigm (Ainsworth et al., 1978) in which the child is observed during play while the caregiver and a stranger enter or leave the room. Adult attachment is typically assessed through the Adult Attachment Interview (Main, Kaplan, \& Cassidy, 1985) or a number of self-report measures, including Hazan \& Shaver's (1987) categorical measure of adult attachment style, the Relationships Questionnaire (Bartholomew \& Horowitz, 1991), the Experiences in Close Relationships (ECR, Brennan et al., 1998), and the ECR-Revised questionnaires (ECR-R, Fraley, Waller, \& Brennan, 2000), all of which measure the two underlying dimensions of attachment.

According to the social-cognitive perspective proposed by Baldwin, Keelan, Fehr, Enns, and Koh-Rangarajoo (1996), in addition to possessing a general attachment style as outlined above, people have multiple attachment working models available in memory that reflect their most important relationships. That is, they possess multiple styles of relating, any one of which may be rendered accessible through contextual priming. This perspective implies that feelings of relational security or insecurity may be situationally activated.

Attachment bonds forged with caregivers in childhood may not only have important consequences for people's adult romantic relationships, but also for their sociopolitical relationships. For instance, the lack of attachment security in interpersonal relationships may lead individuals to form symbolic attachments with groups (Smith, Murphy, \& Coats, 1999), leaders, and institutions (Popper \& Mayseless, 2007) in order to feel protected and secure. With respect to ideology, attachment security renders people less vulnerable to intense or chronic fear and 
doubt, the experience of which may prompt the embrace of conservative ideologies (Fromm, 1941-1994; Jost et al., 2003).

In addition, though the developmental perspective proposes that attachment style remains relatively stable throughout the lifespan, the social-cognitive perspective holds that multiple attachment models are available in memory any may be contextually activated. Attachment style may affect people's chronic sense of security, as well as their views of the self and others; in turn, one's worldviews and sense of security have been shown to correlate with political ideology (Jost et al., 2003). This implies that relatively stable ideological preferences may not only result from chronic attachment styles, but also that ideological preferences may be situationally modulated through the priming of specific attachment models available in memory.

\section{Direct Empirical Investigations}

Four recent empirical investigations directly addressed the relationship between attachment style and political ideology, but they produced somewhat discrepant findings. Working from an evolutionary psychology perspective, Thornhill and Fincher (2007) posited that "differences in political values are manifestations of a species-typical psychological adaptation of attachment, which in turn ontogenetically arises from experiences of early childhood stressors [...] with conservative values providing advantage in familial and other ingroup social relations and with liberal values providing advantage in outgroup relations" (p. 2). Although these authors argue that attachment style was selected due to its value in promoting differentially adaptive political values, especially in relation to interactions with ingroups and outgroups, attachment theory stresses its survival function in keeping infants protected, safe, and alive (Bowlby, 1973).

On the basis of their theoretical perspective, Thornhill and Fincher (2007) hypothesized that individuals who do not experience much childhood stress tend to develop secure attachments and are subsequently drawn to conservative ideologies, whereas those who experience more stressful childhoods tend to become insecurely attached and, in the case of insecure avoidant attachment, are drawn to liberal ideologies. A correlational study conducted with 123 college students appears to support these hypotheses (Thornhill \& Fincher, 2007). In this study, attachment was measured using the Adult Attachment Questionnaire (AAQ; Simpson, Rholes, \& Philips, 1996), a 17-item measure of romantic relationship attachment consisting of two major factors-avoidant and anxious-ambivalent. Childhood stressors were measured with nine items on parental conflict, divorce/separation, and presence/ absence, as well as items assessing the individual's relationship with his/her mother or father, parental personality, and the parents' relationship.

Political ideology was measured with an adapted 28-item version of the C-scale (Eaves et al., 1997), which assesses political attitudes toward a variety of issues. This scale presents subjects with a list of topics and instructs them to indicate whether or not they agree with each topic. We note, however, that some of these topics may have been too vague to lend themselves to a meaningful agree/disagree 
answer. For example, what does it mean to agree/disagree with a "Moral Majority" or "Living Together"? Political ideology was also assessed with two sociopolitical attitude measures: a 30-item Right Wing Authoritarianism scale (RWA; Altemeyer, 1996), which assesses the degree to which individuals endorse established authority, conventional values, and are willing to aggress against devalued outgroups, and a 14-item Social Dominance Orientation scale (SDO; Sidanius, Pratto, \& Bobo, 1994, as cited in Thornhill and Fincher, 2007), which assesses the degree to which individuals prefer hierarchical, as opposed to egalitarian, social arrangements. Both of these attitude constructs are correlated with conservatism (Jost et al., 2003).

As predicted, childhood stressors were negatively associated with secure attachment and positively associated with both types of insecure attachment. More importantly, secure attachment was positively correlated with RWA and C-scale scores but not with SDO, whereas avoidant attachment was negatively correlated with C-scale scores. Lastly, anxious-ambivalent attachment did not correlate with any of the three political values measures. However, multiple regression analyses that controlled for personality, SES, and religiosity showed only a significant positive association between secure attachment and C-scale scores and a negative association between avoidant attachment and $\mathrm{C}$-scale scores. Thus, the positive relationship between secure attachment and RWA was only significant when using Pearson correlation but not multiple regression.

The results of another study, in contrast, suggest that insecure attachment, whether avoidant or anxious-ambivalent, is positively related to RWA and SDO (Weber \& Federico, 2007). These researchers drew on Duckitt's dual process model (Duckitt, 2001; Duckitt, Wagner, du Plessis, \& Birum, 2002), which has been supported by several large investigations (Duckitt, 2001; Duckitt et al., 2002). According to this model, children reared by strict, punitive parents grow up to be socially conformist and to perceive the world as a dangerous and threatening place, fostering authoritarian sociopolitical attitudes and political conservatism. Children reared by cold and unaffectionate parents, on the other hand, grow up to be tough and self-reliant and to see the world as an uncaring, competitive jungle, fostering SDO, and political conservatism (Duckitt, 2001). Duckitt's model does not explicitly specify the type of developmental experiences that foster liberal attitudes, but presumably this would result from having parents who are neither too strict and punitive, nor cold and uncaring.

Extending this framework to encompass interpersonal attachment, Weber and Federico (2007) hypothesized that individuals with anxious-ambivalent attachment would see the world as dangerous and threatening, whereas those with avoidant attachment would see it as cold and competitive. This is in line with findings indicating that security is the primary relationship goal for those with anxiousambivalent attachment, whereas control over others is the primary relationship goal for those with avoidant attachment (Mikulincer, 1998). A correlational study with 225 college students supported these predictions (Weber \& Federico, 2007). In this study, attachment style was assessed with the ECR scale-a well-validated 36-item measure of relational anxiety and avoidance developed by Brennan et al. (1998). Conservatism was measured with two items, the first assessing party identification and the second assessing ideological self-placement. In contrast to the previous 
study in which RWA and SDO were measured with longer versions of these scales, in this study sociopolitical attitudes were measured with a 12 -item version of the RWA scale (see Altemeyer, 1996) and an 8-item version of the SDO scale. The authors also attempted to prime attachment styles by having people imagine a time when they felt distressed but surrounded by caring (versus uncaring) others or to imagine themselves at a grocery store (control). Interestingly, this manipulation had no effect on any of the study variables, which contradicts studies that used similar priming procedures, to be discussed shortly.

The results showed that anxious-ambivalent attachment was positively associated with SDO and marginally associated with RWA, both of which are predictive of conservatism. Interestingly, avoidant attachment was negatively correlated with RWA, suggesting that it is incompatible with authoritarian sociopolitical attitudes and may thus be compatible with political liberalism. At the same time, avoidant attachment was positively associated with SDO, suggesting that avoidant individuals may prefer hierarchical social arrangements; an idea that is compatible with findings that control over others is the primary relationship goal for those with avoidant attachment (Mikulincer, 1998). Interestingly, the study's results indicated that attachment was uncorrelated with both ideological self-placement and party identification (C. M. Federico, personal communication), although these relationships might have been expected. As predicted, the relationship between anxiousambivalent attachment and RWA was mediated by dangerous world perceptions, whereas the relationship between avoidance and SDO was mediated by competitive, uncaring world perceptions.

In sum, Thornhill and Fincher (2007) find a positive association between attachment security and conservative attitudes and a negative association between avoidance and such attitudes, but no significant relationships between attachment styles and RWA and SDO. ${ }^{2}$ In contrast, Weber and Federico (2007) report a positive association between attachment avoidance and SDO and attachment anxiety and RWA, both of which are associated with conservatism (Jost et al., 2003), but no significant relationships with self-reported ideology or party affiliation.

In addition to these correlational studies, two recent experimental investigations have linked attachment security and political attitudes in the context of terror management processes. Previous research has shown that death reminders (mortality salience, MS) lead to increased efforts at bolstering one's worldviews and decreased tolerance for people and ideas that challenge them (Greenberg, Solomon, \& Pyszczynski, 1997). Moreover, MS may also lead people to embrace attitudes and behaviors that are generally more compatible with conservative than with liberal ideologies (Jost et al., 2003), and that death anxiety is associated with conservatism (Jost et al., 2007). However, work by Mikulincer and Florian (2000) suggests that secure attachment might buffer the effects of MS. This is presumably because a secure base provides a psychological defense against distress over one's mortality, and as a result other defenses, including worldview defense, are unnecessary. Building on this study, Weise et al. (2008) and, more recently,

\footnotetext{
${ }^{2}$ With the exception of the positive Pearson correlation between security and RWA, which disappears when potentially confounding variables are controlled in a multiple regression.
} 
Gillath and Hart (in press) have shown that priming secure attachment increases support for liberal and decreases support for conservative political leaders and attitudes. More specifically, in two experiments, Weise et al. (2008) showed that under MS both high dispositional and experimentally primed attachment security were associated with increased support for John Kerry, decreased support for George Bush, decreased support for using extreme military force in the war on terrorism (a conservative stance), and lower self-reported conservatism.

In a set of experiments that aimed to address some methodological concerns with these studies and extend their findings, Gillath and Hart (in press) showed that although priming mortality increased participants' support for the war in Iraq and their endorsement of an aggressive foreign policy toward North Korea (conservative stands), priming security caused the opposite effect and decreased participants' endorsement of such policies. In addition, the security prime buffered MS's effects on these attitudes. Taken together, these experimental studies suggest that secure attachment might be associated with support for liberal leaders and issue positions. However, both Weise et al. (2008) and Gillath and Hart (in press) examined only the effects of secure attachment, thus it is difficult to draw conclusions about the relationships between political orientation and the various types of insecure attachment.

In summary, direct empirical investigations of the relationship between attachment and political ideology have produced conflicting findings. On the one hand, experimental studies indicate that secure attachment is more compatible with a liberal orientation (Weise et al., 2008; Gillath \& Hart, in press). On the other hand, correlational findings suggest that attachment security is associated with political conservatism (Thornhill \& Fincher, 2007). As for insecure attachment, Weber and Federico (2007) showed significant positive association between anxious-ambivalent attachment and conservative sociopolitical values, but the empirical evidence is mixed with respect to avoidant attachment. This type was shown to be positively associated both with high SDO (Weber \& Federico, 2007), which is linked to conservatism, and negatively correlated with C-scale scores (Thornhill \& Fincher, 2007) and RWA scores (Weber \& Federico, 2007), suggesting a possible connection to liberalism.

\section{Indirect Empirical Evidence}

Several studies offer indirect evidence for the relationship between attachment and political ideology by relating attachment to covariates of liberalism and conservatism. In their meta-analysis, Jost et al. (2003) identified a number of dispositional variables that predict conservatism. Conservatives tend to show low openness to experience, low integrative complexity, high dogmatism, mental rigidity, intolerance for ambiguity and uncertainty, high need for closure, order and structure, and high fear of threat and loss. Conservatism is also reliably and positively associated with two situational variables-death anxiety and system instability. Liberals, on the other hand, tend to be more creative and open to experience, and are more likely to pursue novelty, variety, diversity (i.e., openness to outgroup members), and less 
restricted sexual behavior and attitudes (Jost et al., 2003; Jost, 2006; Jost, Nosek, \& Gosling, 2008; Thorisdottir, Jost, Liviatan, \& Shrout, 2007).

All of these variables have been linked to one or more of the attachment styles described earlier. The bulk of the evidence suggests that secure attachment is linked to a liberal orientation. For example, like liberals, securely attached individuals exhibit greater curiosity and information-seeking; lower levels of cognitive closure, mental rigidity, and ethnic stereotyping (Mikulincer, 1997); greater openness toward outgroup members (Mikulincer \& Shaver, 2001); less pronounced propensity toward disgust (Magai, Distel, \& Liker, 1995); and a reduced tendency toward worldview defense (Mikulincer \& Florian, 2000). At the same time, some studies suggest that secure paternal attachment is associated with patriotism (Feshbach, 1991), and secure maternal attachment with intense adult religious commitment given maternal religiosity (Kirkpatrick \& Shaver, 1990), as well as disdain for world government and internationalism (Feshbach, 1991), all of which are in line with political conservatism.

The apparent link between avoidant attachment and political ideology appears somewhat mixed. Some studies show a relationship between avoidant attachment and covariates of conservatism, including preference for order and predictability, intolerance of ambiguity, dogmatism, mental rigidity, the reliance on stable stereotypes in evaluating outgroup members (Mikulincer, 1997) as well as severe judgments of social transgressions following MS (Mikulincer \& Florian, 2000). But a few studies suggest that avoidant attachment is linked with some covariates of liberalism, including sexual pleasure-seeking (Brennan \& Shaver, 1995; Feeney, Noller, \& Patty, 1993; Hazan, Zeifman, \& Middleton, 1994; Miller \& Fishkin, 1997; Rholes, Simpson, Blakely, Lanigan, \& Allen, 1997) and a lack of negative reactions to outgroup members (Mikulincer \& Shaver, 2001).

Finally, anxious-ambivalent attachment has been almost exclusively linked with covariates of conservatism, including preference for order and predictability, intolerance of ambiguity, dogmatism, and mental rigidity (Mikulincer, 1997); severe judgments of social transgressions under MS (Mikulincer \& Florian, 2000); reliance on stable (and negative) stereotypes when evaluating outgroup members (Mikulincer, 1997; Mikulincer \& Shaver, 2001); and an unwillingness to interact with outgroup members (Mikulincer \& Shaver, 2001). Next we describe these studies and findings in more detail.

\section{Information Processing}

In a series of five studies, Mikulincer (1997) examined the relationship between attachment and information processing. Participants were first asked to read the three attachment style descriptions-secure, avoidant, and anxious-ambivalent (Hazan \& Shaver, 1987) — and to indicate the one that best described their feelings. They also completed a variety of self-report and behavioral measures related to information-seeking and cognitive closure. The results indicated that securely attached individuals were higher on curiosity and information-seeking and lower on cognitive closure. Specifically, relative to avoidant and anxiously attached individuals, securely attached individuals scored lower on preference for order 
and predictability, intolerance of ambiguity, and dogmatism; they also exhibited less mental rigidity and were less likely to rely on stable stereotypes when evaluating an ethnic outgroup member.

\section{Emotion}

Disgust sensitivity, another covariate of conservatism (Hodson \& Costello, 2007; Inbar, Pizarro, \& Bloom, 2009), has also been negatively associated with secure attachment. In a study of attachment, socialization and emotion traits, 129 students completed an attachment style measure similar to the one used in the abovementioned studies, as well as the Differential Emotions Scale (Izard, 1972), which assesses the frequency of experienced emotions over a 1-week period (Magai et al., 1995). The results showed that those who were securely attached were less likely to report feeling disgust than were avoidant males and anxious-ambivalent females.

\section{Reactions to Outgroups}

Secure attachment may also enable people to embrace differences in others. Reasoning that the attachment system regulates reactions toward different others, especially outgroups, Mikulincer and Shaver (2001) showed that in five studies priming secure attachment alleviates negative reactions to outgroup members. In the first study, secure priming through the subliminal presentation of positive attachment words, such as "love" and "support," attenuated individuals' negative evaluations of an outgroup target. Neutral and positive affect priming that was unrelated to attachment did not have the same effect. Secure priming did not, however, affect the evaluation of an ingroup member. These results were replicated in a second study using a different priming technique and a behavioral-dependent measure - the willingness to interact with a target outgroup or ingroup member. The third study examined whether perceived threat by the outgroup mediates the relationship between attachment and reactions to outgroups. Secure priming appeared to reduce perceptions of both realistic and symbolic threat, which partially accounted for the attenuated negative evaluation of the outgroup in this experimental condition. The fourth study replicated these findings using another form of threat-self-esteem threat stemming from bogus failure feedback. Finally, the fifth study replicated the attenuating effects of secure priming on outgroup derogation even when the outgroup member threatened important aspects of the participants' worldview. None of the reported results could be accounted for by mood.

Interestingly, when the authors examined the effect of chronic attachment style while controlling for the secure priming manipulation, they found that both secure and insecure avoidant persons refrained from derogating the outgroup. Only the anxious-ambivalent chronic attachment style was associated with negative evaluations of and unwillingness to interact with an outgroup member. Taken together, these results lend support to the idea that relational security leads to greater tolerance and openness toward others, including outgroup members - a tendency 
that is compatible with political liberalism. They also suggest, however, that a chronically avoidant attachment style, unlike an anxious-ambivalent attachment style, may be compatible with openness to outgroups (and perhaps liberalism). In sum, studies that have looked at information processing, emotion, and reactions to outgroups suggest a positive association between secure attachment and liberalism. But other findings imply the opposite pattern.

\section{Religious Commitment}

Secure attachment has been linked to religious commitment. In a newspaper survey study, Kirkpatrick and Shaver (1990) asked participants to retrospectively describe the relationship with their parents by indicating which one of the three (i.e., secure, avoidant, and anxious-ambivalent) paragraph length descriptions of childhood attachment styles best characterized their relationship with their mother and father. Participants also completed measures of religious commitment and belief. The results indicated an interaction between mother's religiosity and retrospectively reported childhood attachment. In comparison to participants reporting insecure maternal attachment, those who reported secure maternal attachment and who perceived their mother to be relatively religious during their childhood reported more religious commitment, greater church attendance, and having a personal relationship with God (Kirkpatrick \& Shaver, 1990). This suggests that when the mother is highly religious, secure maternal attachment is associated with intense adult religiosity, which is a covariate of conservatism (see Jost et al., 2003).

\section{Sexual Pleasure-Seeking}

Furthermore, contrary to evidence that insecure attachment leads to conservative orientation, those with an avoidant attachment style appear to hold more unrestricted sexual attitudes. For example, a study by Brennan and Shaver (1995) showed that individuals who score high on avoidant attachment and related constructs also score high on the Sociosexual Orientation Inventory. High scores on this measure indicate more unrestricted sexuality (e.g., higher number of sexual partners, more diverse sexual experiences, and more favorable attitudes toward casual sex). Comparable results were obtained in other studies with adults (Miller \& Fishkin, 1997). These results were also replicated in a correlational study with adolescents (Feeney et al., 1993), in which avoidant adolescents were more accepting of casual sex than were other attachment groups. In another study that employed diary methodology, however, avoidant adolescent females and anxiousambivalent males were least likely to report engaging in sexual intercourse (Feeney et al., 1993). Overall, these results suggest that avoidant attachment is associated with casual sexual pleasure-seeking, but that for adolescents this effect may be moderated by gender. Given that liberals show more unrestricted sexual behavior and attitudes than conservatives (Jost et al., 2008), these results may provide indirect evidence for the link between insecure avoidant attachment and liberalism. 
Patriotism, Internationalism, and World Government Attitudes

Feshbach (1991) explored the relationship between childhood attachment to parents and subsequent political attitudes. In a study employing three pooled samples consisting of 239 participants, he developed and validated measures of patriotism, nationalism, internationalism, and world government attitudes. Childhood paternal and maternal attachment was measured retrospectively using a number of items developed for the purpose of this study; however, the content of these items is similar to the measures of attachment style. For example, participants rated the extent to which items such as "Whenever I was upset, I found it easy to go to my mother (father) for comfort" and "Often when I needed her (him), my mother (father) wasn't there" were characteristic of their childhood. Given the strong negative correlations obtained between attachment scores and parent-child conflict scores (e.g., "I feel like I am constantly at war with my mother/father"), the scores on the former measure may be taken to indicate a secure childhood attachment. Results showed that (secure) early and current paternal attachment is positively associated with patriotic feelings, that is, love, pride, and commitment to one's country. Early (secure) maternal attachment was inversely related to internationalism - the endorsement of world sharing and the concern for global welfare-as well as pro-world government attitudes. These results should be interpreted with caution as childhood attachment was assessed retrospectively through items that only resembled a measure of secure attachment. Nevertheless, Feshbach's (1991) findings suggest that secure paternal attachment may be associated with patriotism, whereas secure maternal attachment may be associated with negative attitudes toward internationalism and world government. Both of these attitudes are in line with a conservative, rather than liberal, political orientation.

\section{Childrearing Practices}

Lakoff (1996) theorized that implicit family metaphors determine how people relate to politics. According to this author, conservatives espouse the "strict father" metaphor, which is characterized by notions of tough love, protection, authority, strict rules, and their enforcement. Liberals, on the other hand, espouse the "nurturing parent" metaphor, which is characterized by love, empathy, nurturance, as well as the setting of clear rules and guidelines; parents who adhere to this metaphor encourage their offspring to become loving and inclusive as well as responsible and self-reliant. In support of the idea that conservatives adhere to a strict parenting metaphor, research suggests that conservative parents' childrearing practices involve strict discipline (Barker \& Tinnick, 2006; McAdams et al., 2008; Wilcox, 1998). Content analyses of liberals' and conservatives' self-defining life stories also show that liberals are more likely to remember lessons about empathy and openness (McAdams et al., 2008).

However, research also suggests that modern Conservative Protestant's childrearing practices involve physical and verbal expressions of affection (e.g., praise and hugging). Assuming the absence of rebellion, such an affectionate but disciplinarian parenting style may foster secure attachment in offspring (Wilcox, 1998). Securely 
attached Conservative Protestants might be expected to value and embody individual responsibility through their normative behavior (Ellison, Bartkowski, \& Segal, 1996), but to lack independence (Wilcox, 1998) and seek political security-that is, to become secure conservatives. Future research is needed to assess the validity of this hypothesis.

Relating childrearing practices and family dynamics to revolutionary penchants in offspring, Sulloway (1996) argues that laterborns, who receive less parental investment than firstborns and have relatively more autonomous, insecure, and unpredictable childhoods, might become avoidantly attached, as indicated by parent-offspring relationship and conflict measures. At the same time, they might become independent, creative, and rebellious against the status quo, which predisposes them to espouse liberal or radical ideologies. It might be argued that this line of reasoning is in line with the findings of Thornhill and Fincher (2007). If laterborns' childhoods are indeed more insecure and unpredictable, then they might indeed experience more childhood stress, and this could lead them to challenge the status quo (see Thornhill \& Fincher, 2007). More research is needed, however, to ascertain the exact relations among birth order, attachment style, and ideology.

In summary, the indirect empirical evidence concerning the relationship between attachment and ideology is somewhat mixed. First, the overwhelming majority of studies show a positive association between secure attachment and covariates of liberalism, yet a few studies suggest that attachment security is also compatible with conservatism. Similarly, results for attachment avoidance are also equivocal: some studies suggest a relatively strong link between avoidant attachment and covariates of conservatism, yet others find that avoidant attachment may be associated with some covariates of liberalism. We believe that these relationships merit further theorizing and empirical verification, and clarifying them should guide future studies on this topics. Lastly, the relationship between anxious-ambivalent attachment and ideology is least equivocal: anxious-ambivalent style is associated with a number of important covariates of conservatism and thus appears to be more compatible with this orientation.

\section{Criticisms and Future Directions}

In this section, we would like to propose several methodological and theoretical approaches for future research that may help to clarify the relationship between attachment style and political ideology. First, our review suggests that a number of psychological constructs mediate or moderate this relationship; future studies should aim to capture these intervening phenomena by developing more complex, comprehensive models. The model proposed by Weber and Federico (2007), which links attachment to worldviews to sociopolitical attitudes to ideological selfplacement, is a good example of such an approach. The addition of parenting style, birth order, personality traits, and more multifaceted political attitude measures could help enrich and clarify these patterns.

Furthermore, these complex models should be tested with a variety of methods and populations. It is possible that the conflicting results are due to measurement 
issues. The studies we have reviewed relied on a variety of methods (e.g., correlational versus experimental designs, direct versus mediated models, models controlling for confounds versus ones that do not, etc.), a variety of attachment measures (e.g., the AAQ, the ECR, the original, Hazan \& Shaver, 1987 descriptive measure, or modified scales designed by the study authors themselves), as well as a variety of political ideology measures (e.g., C-scale, short and long RWA and SDO scales, ideological self-placement, and support for liberal-conservative leaders and issue positions). Nevertheless, the various attachment measures are derived from a common theoretical conceptualization and are similar in content, and the various ideology measures are empirically associated in predictable ways (Jost et al., 2003). Thus, we were unable to identify a methodological pattern that reliably explained all of the discrepant findings.

A more disconcerting issue is that the vast majority of these studies relied on college student participants. First, college students might not have had enough experience with romantic relationships to accurately report on their relationship behaviors and beliefs. Second, college students and young people in general have notoriously low interest in and knowledge about politics, and they are predominantly liberal (Wattenberg, 2002). Future studies should include more diverse and mature samples.

Finally, researchers on this topic should consider using indirect or implicit measures of attachment, as it is possible that the current self-report scales induce a self-presentation bias. For example, in order to score high on the attachment anxiety dimensions of the ECR scale (Brennan et al., 1998) participants must agree with items such as "I need a lot of reassurance that I am loved by my partner" or "When I'm not involved in a relationship, I feel somewhat anxious and insecure." Such sentiments might be perceived as socially undesirable, especially in a society that emphasizes independence and confidence. Thus, some participants may be reluctant to endorse such items and may end up with artificially low anxious-ambivalence scores.

Aside from these methodological suggestions, we would like to offer a theoretical framework that may illuminate the discrepant associations between attachment style and ideology. Specifically, we propose a distinction between two motivational conceptualizations of attachment as the basis for adopting a political ideology, namely, attachment as a relational need and attachment as a relational habit. First, attachment security may be conceptualized as a basic relational need that, when fulfilled, gives individuals the secure base from which they may embrace the diversity, change, and uncertainty that are more characteristic of liberal ideologies. Alternatively, attachment security may be conceptualized as a relational habit in which individuals become accustomed to the security afforded by their relational bonds and seek out similar levels of security in turning to conservative ideologies. Below we expand on this theoretical distinction.

\section{Attachment Security as a Relational Need}

Attachment security may be conceptualized as a basic relational need that varies in its degree of fulfillment. Attachment security may not only be central to our management of fear and uncertainty and construction of meaning in life (Bowlby, 
1973; Marris, 1991); it may also promote—and attachment insecurity may thwartthe fulfillment of relatively higher order needs (Maslow, 1943). More recent theorizing also posits the existence of a universal need to belong (Baumeister \& Leary, 1995), and similarly, a need for relatedness (Deci \& Ryan, 2000). Maslow's (1943) humanistic hierarchy of needs framework stipulates that "deficiency needs," such as relational love and belonging, are more primitive, higher priority needs than "growth needs," such as self-actualization. That is, secure familial, romantic, and friendship bonds, once established, may allow people to experience: (a) affection, empathy, and compassion for other human beings, (b) a sense of connection to or oneness with humanity, (c) tolerance and perhaps yearning for the new and the unfamiliar, as well as (d) an internalized sense of morality, one that does not rely on external authority. All of these tendencies may prompt the embrace of liberal/ humanistic ideologies that advocate social change toward greater equality.

The degree to which the need for attachment security is satisfied may vary both dispositionally and situationally. Dispositionally, people with a secure attachment style may be protected against fear, threat, uncertainty, and meaninglessness. That is, in the face of threat, including existential threat, securely attached individuals (but not those for whom security has become an immutable expectancy) may draw upon their relational resources to buffer existential and epistemic anxiety, uncertainty, and meaninglessness, thus remaining open to the political change advocated by liberal ideologies. Situationally, people may be experimentally "secured," for instance by priming secure attachment, as well as situationally "insecured," for instance by increasing MS.

Thus a satisfied need for secure attachment may give people a secure base from which they can self-actualize and embrace more liberal or humanistic ideologies (secure $\rightarrow$ liberal). In contrast, the feelings of threat, uncertainty, and insecurity that may stem from an unsatisfied need for attachment among anxious-ambivalent and avoidant individuals may prompt an "escape from freedom" (Fromm, 1941-1994) and the compensatory embrace of conservative ideologies that emphasize security (insecure $\rightarrow$ conservative). In line with our conceptualization of attachment as a relational need, the fulfillment of which fosters a politically liberal orientation, the overwhelming majority of the research reviewed here suggests that securely attached people tend to be liberal, whereas anxious-ambivalent and avoidant people are more likely to be conservative.

\section{Attachment Security as a Relational Habit}

Attachment security, however, may also result in a relational habit, or adaptation, that drives expectancies for future security versus insecurity in both interpersonal and political spheres. Specifically, habitual relational security may foster an attraction to conservative ideologies that engender stability and certainty by maintaining the status quo. Such a process will yield securely attached conservatives (secure $\rightarrow$ conservative). In contrast, habitual relational avoidance may foster a tolerance for and even attraction to the uncertainty and instability that characterize change-promoting liberal ideologies. In addition, because such individuals are habituated to low security and intimacy with their parents and/or romantic partners, they might view 
themselves as more or less equally connected to all humans in general (i.e., humankind becomes their symbolic attachment figure). As a result, they may come to embrace internationalism and global welfare, which are predominantly liberal ideals. Conceptualizing attachment as a relational habit thus may help explain why we might see avoidantly attached liberals (avoidant $\rightarrow$ liberal).

In sum, although our conceptual distinction between attachment as a relational need versus habit is tentative and in need of empirical verification, it could offer some clues about how to interpret inconsistent evidence concerning attachment and ideology. The basic theoretical prediction is that a satisfied need for attachment security leads to political liberalism, whereas an unsatisfied need for attachment security leads to political conservatism. In contrast, a habit of attachment security leads to political conservatism, whereas a habit of attachment insecurity, especially attachment avoidance, leads to political liberalism. Of course, before we can test this model we must first find a way to determine whether a person's attachment style reflects a need or a habit. Nevertheless, we hope that this framework may offer some theoretical guidance for future study on this topic. It is also our hope that future research continues to examine and refine the complex relationship between individual psychological predispositions, such as relational attachment style, and the subsequent attraction to various systems of belief, such as political ideology.

Open Access This article is distributed under the terms of the Creative Commons Attribution Noncommercial License which permits any noncommercial use, distribution, and reproduction in any medium, provided the original author(s) and source are credited.

\section{References}

Ainsworth, M. D. S. (1991). Attachments and other affectional bonds across the life cycle. In C. M. Parkes, J. Stevenson-Hinde, \& P. Marris (Eds.), Attachment across the life cycle (pp. 33-51). London: Routledge.

Ainsworth, M. D. S., Blehar, M. C., Waters, E., \& Wall, S. (1978). Patterns of attachment: A psychological study of the strange situation. Hillsdale: Erlbaum.

Alford, J. R., Funk, C. L., \& Hibbing, J. R. (2005). Are political orientations genetically transmitted? American Political Science Review, 99, 153-167.

Altemeyer, B. (1996). The authoritarian specter. Cambridge: Harvard University Press.

Baldwin, M. W., Keelan, J. P. R., Fehr, B., Enns, V., \& Koh-Rangarajoo, E. (1996). Social-cognitive conceptualization of attachment working models: Availability and accessibility effects. Journal of Personality and Social Psychology, 71, 94-109.

Barker, D. C., \& Tinnick, J. D. (2006). Competing visions of parental roles and ideological constraint. American Political Science Review, 100, 249-263.

Bartholomew, K., \& Horowitz, L. M. (1991). Attachment styles among young adults: A test of a fourcategory model. Journal of Personality and Social Psychology, 61(2), 226-244.

Baumeister, R. R., \& Leary, M. R. (1995). The need to belong: Desire for interpersonal attachments as a fundamental human motivation. Psychological Bulletin, 117, 497-529.

Block, J., \& Block, J. H. (2006). Nursery school personality and political orientation two decades later. Journal of Research in Personality, 40, 734-749.

Bonanno, G. A., \& Jost, J. T. (2006). Conservative shift among high-exposure survivors of the September 11th Terrorist Attacks. Basic \& Applied Social Psychology, 28, 311-323.

Bowlby, J. (1973). Attachment and loss: Vol. 2. Separation, anxiety and anger.. New York: Basic Books.

Brennan, K. A., Clark, C. L., \& Shaver, P. R. (1998). Self-report measurement of adult romantic attachment: An integrative overview. In J. A. Simpson \& W. S. Rholes (Eds.), Attachment theory and close relationships (pp. 46-76). New York: Guilford Press. 
Brennan, K. A., \& Shaver, P. R. (1995). Dimensions of adult attachment, affect regulation, and romantic relationship functioning. Personality and Social Psychology Bulletin, 23, 23-31.

Caprara, G. V., \& Zimbardo, P. G. (2004). Personalizing politics: A congruency model of political preference. American Psychologist, 59, 581-594.

Cassidy, J. (1994). Emotion regulation: Influences of attachment relationships. Monographs of the Society for Research in Child Development. The Development of Emotion Regulation. Biological and Behavioral Considerations (Vol. 59, pp. 228-249).

Deci, E. L., \& Ryan, R. M. (2000). The "what" and "why" of goal pursuits: Human needs and the selfdetermination of behavior. Psychological Inquiry, 11, 227-268.

Duckitt, J. (2001). A dual-process cognitive-motivational theory of ideology and prejudice. In M. P. Zanna (Ed.), Advances in experimental social psychology (Vol. 33, pp. 41-113). San Diego: Academic Press.

Duckitt, J., Wagner, C., du Plessis, I., \& Birum, I. (2002). The psychological bases of ideology and prejudice: Testing a dual process model. Journal of Personality and Social Psychology, 83, 75-93.

Eaves, L., Martin, N., Heath, A., Schieken, R., Meyer, J., Silberg, J., et al. (1997). Age changes in the causes of individual differences in conservatism. Behavior Genetics, 27, 121-124.

Ellison, C. G., Bartkowski, J. P., \& Segal, M. L. (1996). Do conservative Protestants spank more often? Further evidence from the National Survey of Families and Households. Social Science Quarterly, 77, 663-673.

Feeney, J. A., Noller, P., \& Patty, J. (1993). Adolescents' interactions with the opposite sex: Influence of attachment style and gender. Journal of Adolescence, 16, 169-186.

Feshbach, S. (1991). Attachment processes in adult political ideology: Patriotism and nationalism. In J. L. Gewirtz \& W. M. Kurtines (Eds.), Intersections with attachment (pp. 207-226). Hillsdale, NJ: Erlbaum.

Fraley, C. R., \& Shaver, P. R. (2000). Adult romantic attachment: Theoretical developments emerging controversies and unanswered questions. Review of General Psychology, 4, 132-154.

Fraley, R. C., Waller, N. G., \& Brennan, K. A. (2000). An item-response theory analysis of self-report measures of adult attachment. Journal of Personality and Social Psycology, 78, 350-365.

Fromm, E. (1941/1994). Escape from freedom. New York: Farrar \& Rinehart.

Gillath, O., \& Hart, J. (in press). The effects of psychological security and insecurity on political attitudes and leadership preferences. European Journal of Social Psychology.

Greenberg, J., Solomon, S., \& Pyszczynski, T. (1997). Terror management theory of self-esteem and cultural worldviews: Empirical assessments and conceptual refinements. In M. Zanna (Ed.), Advances in experimental social psychology. New York: Academic Press.

Griffin, D., \& Bartholomew, K. (1994). Models of the self and other: Fundamental dimensions underlying measures of adult attachment. Journal of Personality and Social Psychology, 67, 430-445.

Hazan, C., \& Shaver, P. (1987). Romantic love conceptualized as an attachment process. Journal of Personality and Social Psychology, 52, 511-524.

Hazan, C., Zeifman, D., \& Middleton, K. (1994, July). Adult romantic attachment, affection, and sex. Paper presented at the 7th International Conference on Personal Relationships, Groningen, The Netherlands.

Higgins, E. T. (1997). Beyond pleasure and pain. American Psychologist, 1997, 1280-1300.

Hodson, G., \& Costello, K. (2007). Interpersonal disgust, ideological orientations, and dehumanization as predictors of intergroup attitudes. Psychological Science, 18, 691-698.

Inbar, Y., Pizarro, D. A., \& Bloom, P. (2009). Conservatives are more easily disgusted than liberals. Cognition and Emotion, 23, 714-725.

Izard, C. E. (1972). Patterns of emotions. New York: Academic Press.

Jost, J. T. (2006). The end of the end of ideology. American Psychologist, 61, 651-670.

Jost, J. T., Glaser, J., Kruglanski, A. W., \& Sulloway, F. (2003). Political conservatism as motivated social cognition. Psychological Bulletin, 129, 339-375.

Jost, J. T., Napier, J. L., Thorisdottir, H., Gosling, S. D., Palfai, T. P., \& Ostafin, B. (2007). Are needs to manage uncertainty and threat associated with political conservatism or ideological extremity? Personality and Social Psychology Bulletin, 33, 989-1007.

Jost, J. T., Nosek, B. A., \& Gosling, S. D. (2008). Ideology: Its resurgence in social, personality, and political psychology. Perspectives on Psychological Science, 3(2), 126-136.

Kirkpatrick, L. A., \& Shaver, P. R. (1990). Attachment theory and religion: Childhood attachments, religious beliefs, and conversion. Journal for the Scientific Study of Religion, 29, 315-334.

Lakoff, G. (1996). Moral politics: What conservatives know that liberals don't. Chicago: University of Chicago Press. 
Lamb, M. E. (1997). The development of father-infant relationships. In M. E. Lamb (Ed.), The role of the father in child development (pp. 104-120). New York: Wiley.

Magai, C., Distel, N., \& Liker, R. (1995). Emotion socialization, attachment, and patterns of adult emotion traits. Cognition and Emotion, 9, 461-481.

Main, M., Kaplan, K., \& Cassidy, J. (1985). Security in infancy, childhood, and adulthood: A move to the level of representation. Monographs of the Society for Research in Child Development, 50 (1-2, Serial No. 209).

Marris, P. (1991). The social construction of uncertainty. In C. M. Parkes, J. Stevenson-Hinde, \& P. Marris (Eds.), Attachment across the life-cycle (pp. 77-90). London: Tavistock/Routledge.

Maslow, A. H. (1943). A theory of human motivation. Psychological Review, 50, 370-396.

McAdams, D. P., Albaugh, M., Farber, E., Daniels, J., Logan, R. L., \& Olson, B. (2008). Family metaphors and moral intuitions: How conservatives and liberals narrate their lives. Journal of Personality and Social Psychology, 95(4), 978-990.

McCrae, R. R. (1996). The social consequences of experiential openness. Psychological Bulletin, 120, 323-337.

Mikulincer, M. (1997). Adult attachment style and information processing: Individual differences in curiosity and cognitive closure. Journal of Personality and Social Psychology, 72, 1217-1230.

Mikulincer, M. (1998). Attachment working models and the sense of trust: An exploration of interaction goals and affect regulation. Journal of Personality and Social Psychology, 74, 1209-1224.

Mikulincer, M., \& Florian, V. (2000). Exploring individual differences in reactions to mortality salience: Does attachment style regulate terror management mechanisms? Journal of Personality and Social Psychology, 79, 260-273.

Mikulincer, M., \& Shaver, P. R. (2001). Attachment theory and intergroup bias: Evidence that priming the secure base schema attenuates negative reactions to outgroups. Journal of Personality and Social Psychology, 81, 97-115.

Miller, L. C., \& Fishkin, S. A. (1997). On the dynamics of human bonding and reproductive success: Seeking windows on the adapted-for human environmental interface. In J. Simpson \& D. Kenrick (Eds.), Evolutionary social psychology (pp. 197-235). Mahwah, NJ: Erlbaum.

Popper, M., \& Mayseless, O. (2007). Reliance on leaders and social institutions: An attachment perspective. Attachment and Human Development, 9(1), 73-93.

Rholes, W. S., Simpson, J. A., Blakely, B. S., Lanigan, L., \& Allen, E. A. (1997). Adult attachment styles, the desire to have children, and workingmodels of parenthood. Journal of Personality, 65, 357-385.

Shaver, P., \& Mikulincer, M. (2002). Attachment-related psychodynamics. Attachment and Human Development, 4, 133-161.

Simpson, J. A., Rholes, W. S., \& Philips, D. (1996). Conflict in close relationships: An attachment perspective. Interpersonal Relations and Group Processes, 71, 899-914.

Smith, E. R., Murphy, J., \& Coats, S. (1999). Attachment to groups: Theory and management. Journal of Personality and Social Psychology, 77, 94-110.

Sulloway, F. J. (1996). Born to rebel: Birth order family dynamics and creative lives.. New York: Pantheon Books.

Thorisdottir, H., Jost, J. T., Liviatan, I., \& Shrout, P. (2007). Psychological needs and values underlying left-right political orientation: Cross-national evidence from Eastern and Western Europe. Public Opinion Quarterly, 71(2), 175-203.

Thornhill, R., \& Fincher, C. L. (2007). What is the relevance of attachment and life history to political values? Evolution and Human Behavior, 28, 215-222.

Trinke, S. J., \& Bartholomew, K. (1997). Hierarchies of attachment relationships in young adulthood. Journal of Social and Personal Relationships, 14(5), 603-625.

Waters, E. (2002). Live long and prosper. Retrieved March 5, 2009, from http://www.psychology. sunysb.edu/attachment/gallery/live_long/live_long.html.html.

Wattenberg, M. P. (2002). Where have all the voters gone? Cambridge, MA: Harvard University Press.

Weber, C., \& Federico, C. M. (2007). Interpersonal attachment and patterns of ideological belief. Political Psychology, 28, 389-416.

Weise, D. R., Pyszczynski, T., Cox, C., Arndt, J., Greenberg, G., Solomon, S., et al. (2008). Interpersonal politics: The role of terror management and attachment processes in shaping political preferences. Psychological Science, 19(5), 448-455.

Wilcox, W. B. (1998). Conservative protestant childrearing: Authoritarian or authoritative? American Sociological Review, 63, 796-809. 